\title{
SOME FEATURES OF LEUKAEMIA MORTALITY
}

\author{
BY
}

DAVID HEWITT

From the Social Medicine Unit, University of Oxford

During 1953 there were just over forty deaths per week from leukaemia in England and Wales. This was, of course, a small proportion of the total number of deaths, but the years of potential life lost by death from leukaemia were disproportionately great: greater, for example (reckoning life to the age of 75) than those lost by. death from peptic ulcer, non-respiratory tuberculosis, or all diseases conventionally attributed to viruses. Leukaemia derives an added importance from the fact that its rate of increase in recent years has been greater than that of any other cause of death except lung cancer and coronary thrombosis. Yet hardly anything has been written about leukaemia from the epidemiological point of view.

There seem to be two reasons for this neglect: the number of cases observed by a single clinician is rarely sufficient to suggest any aetiological hypothesis; and a suspicion exists (also expressed in connexion with lung cancer and coronary thrombosis) that standards of diagnosis may have varied from time to time and from place to place in such a way as to vitiate any statistical analysis. The present study therefore suffers from two faults: that it had to be based entirely on secondary sources, and that it had to be conducted as if diagnostic standards were always uniform. This may not deprive the conclusions of all value; for example, the effect of regional variation in speed of diagnosis is kept to a minimum by restricting attention to death certificates.

\section{Type, Sex, and Age Distribution of Leukaemia DeATHS}

Since the introduction of the Sixth Revision of the "International Classification of Diseases and Causes of Death" (in which leukaemia has been transferred from "Diseases of the Blood and Blood-forming Organs" to "Malignant Neoplasms"), the national statistics of the United Kingdom have distinguished three types of leukaemia:

(a) Myeloid (45 per cent. of all leukaemia deaths, 1950-53);

(b) Lymphatic (37 per cent.);

(c) Monocytic (9 per cent.).

No distinction is made between acute and chronic forms of the disease, but deaths which have not been classified as belonging to any of the three main groups are described either as "acute leukaemia of unspecified type" (6 per cent.) or as "other and unspecified leukaemia" ( 3 per cent.).

There is a slight excess of males among persons dying of leukaemia. This is principally due to the high sex ratio $\left(\frac{M}{F} \times 100\right)$ in the lymphatic type.

Sex ratios in the years $1950-53$ were:

$$
\left.\begin{array}{lll}
\text { Lymphatic leukaemia } & . . & 58 \\
\text { Monocytic leukaemia } & . . & 54 \\
\text { All types of leukaemia } & . . & 53 \\
\text { All causes of death } & . & 51 \\
\text { Myeloid leukaemia } & . . & 49
\end{array}\right\} \text { per cent. male }
$$

The contrast between the two main groups is much too large to be attributed to chance $\left(\chi^{2}\right.$ with one degree of freedom, 59.01;P<10-10). Moreover it has not resulted from the greater proportion of females at risk in the elderly population, since this would have tended to lower the sex ratio for lymphatic leukaemia in relation to that for the myeloid type (see below). Nor can this result be attributed to variations in diagnosis. There is therefore some aetiological difference between the two main types of leukaemia, which must be associated with a difference between the sexes in exposure or susceptibility to leukaemogenic influences. 
The relationship between age and leukaemia mortality is shown in Fig. 1, which indicates that, though the death rate is rather high among children, the heaviest mortality during 1950-53 was experienced by men and women between the ages of 65 and 80.

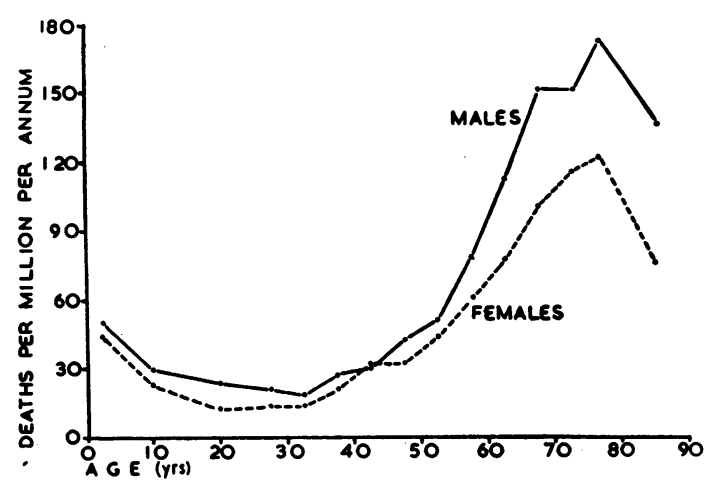

Fig. 1.-Mortality from leukaemia, by sex and age, England and Wales 1950-53.

The apparent tendency for risk of death from leukaemia to decline after the age of 80 may be merely a transient feature of the age-specific mortality curve. This is shown by Fig. 2 which presents a longitudinal or "cohort" view of the mortality experienced by groups of persons born in different decades. Members of the 1871 cohort were subject to a much greater risk of death from leukaemia during their early eighties than at any previous period of their lives. Later "cohorts" have also experienced a much more rapid increase during adult life in the risk of death from leukaemia than is suggested by the cross-sectional view shown in Fig. 1. Thus the age-curve for death from leukaemia seems likely to take on a shape something like that regarded by Nordling (1953) as typical of malignant diseases.

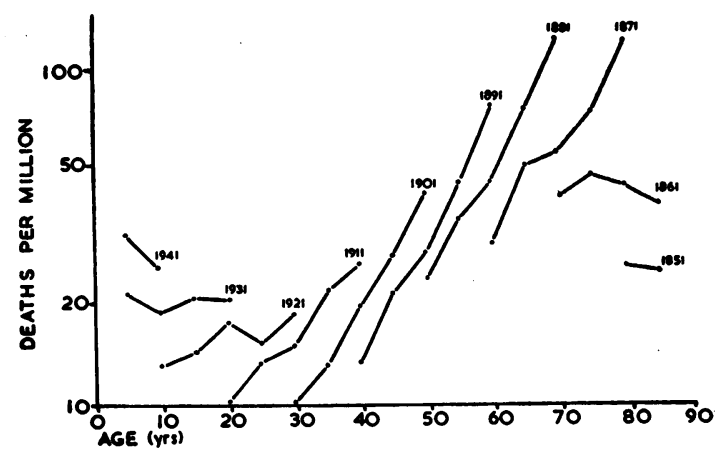

Fio. 2.-Mortality from leukaemia, by approximate date of birth; log. scale, sexes combined.
Different age groups show wide contrasts in the proportion of deaths ascribed to each type of leukaemia (Fig. 3). Among young children the lymphatic type is nearly twice as common as the myeloid type. By the age of $\mathbf{3 0}$ these proportions are reversed, but lymphatic leukaemia appears to increase in relative importance during the forties and fifties, and again becomes the commonest type at ages over 70. This relationship between age and the ratio of lymphatic to myeloid incidence is of interest because comparisons will be made below between populations in which no distinction as to type of leukaemia is possible. There is a slight presumption that when a population has an excess of leukaemia in the central age groups this may be associated with a relatively heavy mortality from the myeloid type. Conversely, if a population is found to suffer an excess of leukaemia which increases with age, then this may be associated with a heavy mortality from the lymphatic type.

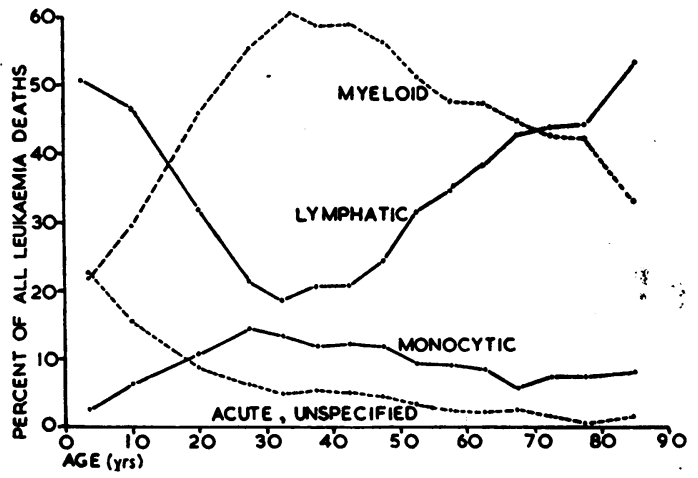

Fig. 3.-Relative frequency of types of leukaemia, by age.

Fig. 3 also shows that the "acute unspecified" type is commonest, as would be expected, at the youngest ages, and that it declines in relative importance throughout life.

\section{Leukaemia Mortality IN CHIIDREN UNDER Five YeARS OF AGE}

The peak of mortality in the under-5 age group, unlike the later peak, seems to be a permanent feature of leukaemia. It is possible to locate this early peak more accurately by using the numbers of deaths and population at risk which are available for individual years of life from 0 to 5 . These figures reveal a marked discontinuity in the risk of death from leukaemia during early childhood (Fig. 4, opposite).

In the first few months of life the death rate was between 25 and 30 per million and in the second year of life only a little higher. But in the third year it rose to twice its original level with a further small 


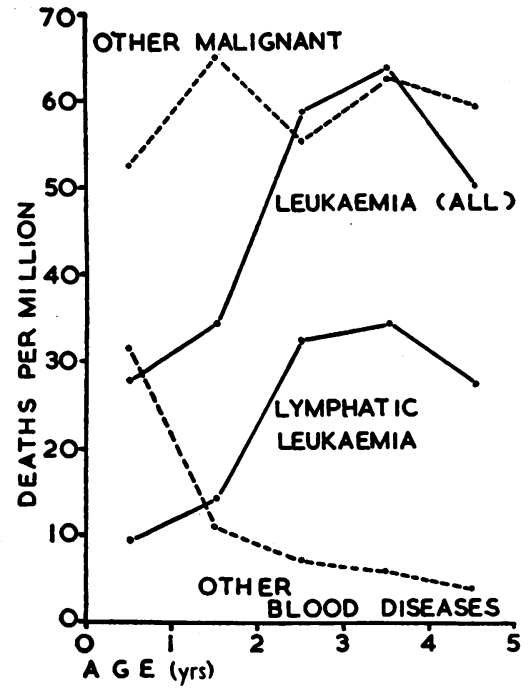

Fig. 4.-Mortality from leukaemia in children under 5 years of age, 1950-53.

rise in the fourth year. The death rate from lymphatic leukaemia among 2-year-olds was more than three times as great as among infants of 0 to 12 months. This abrupt, upward change in mortality has no parallel in any other cause of death for which statistics are available*. It is quite different from the age-gradient for other malignant diseases and for non-neoplastic diseases of the blood and bloodforming organs. This phenomenon appears to affect boys more than girls, and to have become more important during recent years (Figs $5 \mathrm{~A}$ and 5B).

Statistics of deaths in the U.S.A. show that a rise in mortality between the second and third years of life has been a feature of leukaemia in that country also, at least since the "cohort" of 1931. Moreover this rise seems to have been greater for the first post-war babies (Table I).

\section{TABLE I}

U.S.A. LEUKAEMIA DEATHS IN ONE-YEAR-OLD BABIES AND IN TWO-YEAR-OLD BABIES DURING THE FOLLOWING CALENDAR YEAR, BY APPROXIMATE YEAR OF BIRTH

\begin{tabular}{c|c|c|c}
\hline \multirow{2}{*}{ Yr of Birth } & \multicolumn{2}{|c|}{ Deaths } & \multirow{2}{*}{$\begin{array}{c}\text { Percentage } \\
\text { Excess of } \\
\text { 2-yr-olds }\end{array}$} \\
\cline { 2 - 3 } & 1-yr-olds & 2-yr-olds & 164 \\
\hline $1931-33$ & 161 & 216 & 36 \\
$1933-36$ & 185 & 252 & 27 \\
$1937-39$ & 256 & 326 & 38 \\
$1940-42$ & 274 & 378 & 30 \\
$1943-45$ & 331 & 429 & 76 \\
$1946-48$ & 348 & 612 & \\
\hline
\end{tabular}

* The incidence of tuberculous meningitis increases between the first and second years. American figures suggest that cancers of the brain and of the kidney are commoner in the second than in the first year of life.
At least two American groups-Bufkin and Davison (1943) and Cooke (1942)-have had under review sufficient hospital cases of leukaemia to show that a peak occurs in the third and fourth years of life.

Cooke asserts that the age-incidence curve of leukaemia in childhood follows that of the acute childhood infections which she considers to be important factors in the causation of leukaemia. As far as fatal cases of childhood exanthemata are concerned this is certainly not true, but the age-curve for leukaemia may conceivably follow the ageincidence curve of non-fatal cases. However, Cooke's hypothesis would in any case not explain the recent accentuation of the leukaemia peak in childhood.

\section{REgIONAL VARIATION WITHIN ENGLAND AND WALES}

Death from individual causes in the different regions of England and Wales are published only for a selected list of diseases, which did not include leukaemia until 1950 . Consequently, only 4 years' records of leukaemia deaths (numbering 7,923) are available for analysing regional variations in mortality.

The method of analysis used here is identical with that used by the Registrar-General in his studies of occupational mortality. Age-specific death-rates for the country as a whole have been applied to the numbers of persons of various ages in each local population to obtain a "standard" number of deaths.

When divided into the number of deaths in any area, this provides a mortality ratio, conventionally expressed as a percentage. For the present purpose nine age groups have been used for each sex so that the standard number of deaths for a region is the sum of eighteen separately-calculated expectations. 
The results of this analysis are shown in Table II. There is a fairly regular gradient in leukaemia mortality from a relatively low level in the north of England to a level about half as high again in the south. That is, the variation is about as great as (but in a generally contrary direction to) the regional variation in stillbirths and neonatal deaths, both of which are considered to be fairly sensitive to local conditions. This north-to-south gradient may owe something to the varying proportions of each economic class which are found in the different regions, but the regional differences in leukaemia are too large to be regarded as secondary to economic differences. The same general gradient can be observed in mortality ratios calculated for the sexes separately.

TABLE II

LEUKAEMIA MORTALITY IN THE STANDARD REGIONS OF ENGLAND AND WALES

STANDARDIZED FOR AGE AND SEX, 1950-53

\begin{tabular}{|c|c|c|c|}
\hline \multirow[b]{2}{*}{ Region } & \multicolumn{2}{|c|}{ No. of Deaths } & \multirow{2}{*}{$\begin{array}{c}\text { Mortality } \\
\text { Ratio }\end{array}$} \\
\hline & Actual & $\begin{array}{c}\text { Standard- } \\
\text { ized }\end{array}$ & \\
\hline 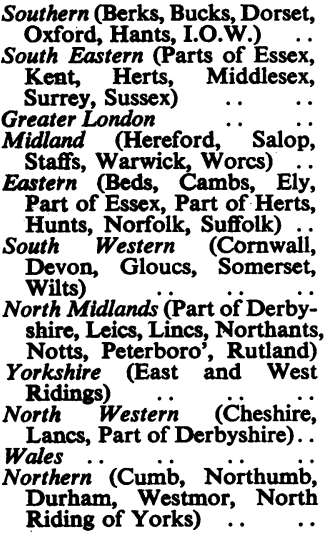 & $\begin{array}{r}569 \\
683 \\
1,069 \\
421 \\
\\
460\end{array}$ & $\begin{array}{r}580 \cdot 34 \\
569 \cdot 03 \\
606 \cdot 25 \\
735 \cdot 93 \\
1,162 \cdot 01 \\
471 \cdot 12 \\
553 \cdot 69\end{array}$ & $\begin{array}{l}95 \\
94 \\
93 \\
92 \\
89 \\
83\end{array}$ \\
\hline
\end{tabular}

None of the great cities of England and Wales, apart from London, had an exceptionally high or low leukaemia death rate during $1950-52 .^{*}$ In particular the nine County Boroughs in which there are teaching hospitals registered 618 deaths com-' pared with a standard number of 606 . One would hardly have expected such a close agreement between registered and standard deaths in these boroughs if local variations in diagnostic standards

\footnotetext{
- For county boroughs and for subdivisions of greater London the only figures which give the age-distribution of the populations at risk are those from the 1951 Census. A separate analysis had therefore to be made for the three years immediately surrounding the census date, this time using only eight age groups in each sex.
}

had had any important effect on the reported death rate from leukaemia.

So slight are the differences between the county boroughs that regional variation can be shown to arise chiefly from variations in rates outside the main towns. The ten standard regions other than London have been grouped in two sets of five (on the basis of their mortality ratios), and the registered and standard deaths have been aggregated for each set (Table III).

TABLE III

\begin{tabular}{|c|c|c|}
\hline \multirow[b]{2}{*}{ Regions } & \multicolumn{2}{|c|}{ Mortality Ratio } \\
\hline & $\begin{array}{l}\text { Aggregate of } \\
\text { County } \\
\text { Boroughs }\end{array}$ & $\begin{array}{l}\text { Aggregate of } \\
\text { Administrative } \\
\text { Counties }\end{array}$ \\
\hline $\begin{array}{l}\text { Five with high mortality ratios } \\
\text { Five with low mortality ratios }\end{array}$ & $\begin{array}{r}100 \cdot 7 \\
96 \cdot 4\end{array}$ & $\begin{array}{r}107 \cdot 8 \\
84 \cdot 4\end{array}$ \\
\hline Difference.. & $4 \cdot 3$ & $23 \cdot 4$ \\
\hline
\end{tabular}

For leukaemia, a simple comparison between urban and rural areas cannot be made, for in the north of England urban mortality tends to exceed rural mortality, while in the south the reverse is the case. Even this is an over-simplification, as is shown by subdivision of the largest region in the south. Within Greater London the central L.C.C. area (which has the greater affinity to county boroughs in other parts of the country) had a higher mortality than the outer ring (120 compared with 110). The L.C.C. area is, however, by no means homogeneous. Four contiguous Metropolitan Boroughs in the north-west (Chelsea, Westminster, St. Marylebone and Hampstead) had together a mortality ratio of 185 , while four others on the south side of the river (Southwark, Bermondsey, Lambeth, and Camberwell) registered only 93 per cent. of their standard deaths.

The excess of leukaemia deaths in the L.C.C. area as a whole was almost identical for the two sexes (male mortality ratio, 113; female, 114) but the excess increased with age:

\begin{tabular}{c|c}
\hline Age (yrs) & Mortality Ratio \\
\hline $0-4$ & 93 \\
$5-24$ & 102 \\
$25-44$ & 105 \\
$45-64$ & 119 \\
$65-74$ & 121 \\
$75+$ & 203 \\
\hline
\end{tabular}

This tendency for regional variation to be greatest in the oldest age groups can also be demonstrated in areas outside London. 


\section{COMPaRison OF ENGLAND AND Wales WITH OTHER COUNTRIES}

The method of comparison applied to the regions of England and Wales can be extended to other countries which publish statistics of deaths from leukaemia, provided that there is also available a contemporary estimate of the populations at risk in a number of age groups (Table IV). The sources of the statistics used are given with other references at the end of the paper. In each case the comparison is based on the age-specific death rates current in England and Wales during the years for which the other country's figures were available. The number of age groups used in the standardization was in every case greater than the number for which separate mortality ratios are shown in Table IV).

Scotland.-The number of deaths from leukaemia registered during $1950-52$ was 635 . This is very close to the 659 deaths which would have been expected on the basis of the age-specific rates for England and Wales. The ratio of myeloid to lymphatic cases was, however, higher than in England and Wales. This observation may be related to the apparent tendency for the Scottish death rate to be relatively high during the middle part of life, when the proportion of myeloid cases is highest (Fig. 3). As in England and Wales, lymphatic leukaemia in Scotland showed a greater excess of males than other types:

Lymphatic leukaemia ..

All forms of leukaemia ..

Myeloid leukaemia ...

$\left.\begin{array}{l}58 \\ 52 \\ 47\end{array}\right\}$ per cent. male

Northern Ireland.-Deaths attributed to leukaemia were significantly less common during 1950-52 than in England and Wales as a whole. This difference was most conspicuous among the older age groups who suffered only about a half of their "standard" deaths. Between the ages of 35 and 54, on the other hand, there was a clear excess of leukaemia deaths in Northern Ireland. This may mean an occupational risk somewhere in the six counties, partly because of the age group involved, but chiefly because the entire excess occurred among men.
These "extra" deaths cannot be located precisely from the published statistics for localities of Northern Ireland, since these figures do not separate leukaemia from Hodgkin's disease.

Eire.-The mortality ratio is even lower than for the northern part of the island, and again the greatest deficit in "expected" deaths was in the oldest age group.

U.S.A.-During 1949-50 leukaemia mortality was much higher than in England and Wales; the high total resulted from the large number of deaths attributed to leukaemia among the white population. Whereas young men and women on each side of the Atlantic appear to be about equally liable to die of leukaemia, the rates for individuals who were past working age were two or three times higher in America than in England. This suggests the possibility of a difference in diagnostic standards, at least in elderly patients. But the differences between the two countries for neoplasms of some other sites, where the diagnosis is rarely in doubt, are equally great. A national difference in diagnostic practice could not explain both comparisons in Table IV, since non-white Americans had, generally, speaking, much lower death rates from leukaemia than the English. Despite the very low rates for non-whites at each extreme of life, the mortality ratio for coloured persons in the age group 35-44 was even higher than that for white Americans. A closely parallel finding for cancer of the lung has been reported by Hoffman and Gilliam (1954), who comment:

This age differential in rates does not appear to be consistent with the view that the lower total mortality for the non-white population is due to inadequate diagnostic facilities.

Mortality differences between the white and coloured population of the United States are variously interpreted as being due to racial, social, or geographical factors. There is little evidence that racial or genetic factors are important in human leukaemia, however, and no study of the geographical distribution of the disease within the United States is yet available. It therefore seems reasonable to regard the relatively low rates among non-whites as evidence of the influence of social conditions (see below).

TABLE IV

LEUKAEMIA MORTALITY IN CERTAIN COUNTRIES, EXPRESSED AS PERCENTAGE OF CONTEMPORARY MORTALITY IN ENGLAND AND WALES, STANDARDIZED FOR AGE AND SEX

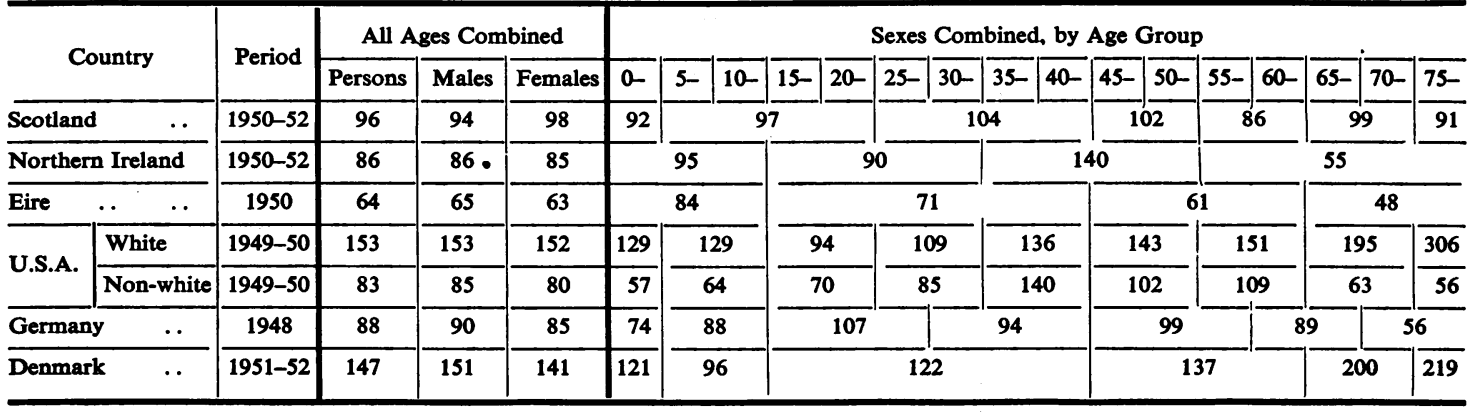


Germany.-Although the Federal Republic had, during 1948, a death rate from leukaemia which was appreciably lower than the contemporary rate in England and Wales, persons of working age were as liable to die of leukaemia in Germany as in Britain. The difference between the countries was due to the relatively low rates for the very young and very old in Germany; the oldest age groups showed the greatest contrast.

Denmark.-Here the population is considerably smaller than that of Scotiand, yet had as many deaths from leukaemia in 2 years as did Scotland in 3 years. This country provides the most challenging example so far revealed of a geographical differential in leukaemia. In environmental and social conditions Denmark must more closely resemble Britain than it does the United States. Yet in Denmark leukaemia mortality is approximately equal to that in the United States. The payment of a notification fee for cases of leukaemia may stimulate Danish physicians to make the diagnosis in cases where it would have been overlooked by a British doctor, but this seems unlikely to provide the full explanation.

\section{SOCIAL AND OCCUPATIONAL INCIDENCE OF LEUKAEMIA}

The last full occupational mortality analysis (Registrar-General, 1938), now more than 20 years out of date, includes leukaemia together with Hodgkin's disease under "Leukaemia, etc.".

Social Class.-This group of diseases occurred in excess at the upper end of the economic scale, particularly among older persons. For males of all ages over 16 the Social Class mortality ratios were as follows:*

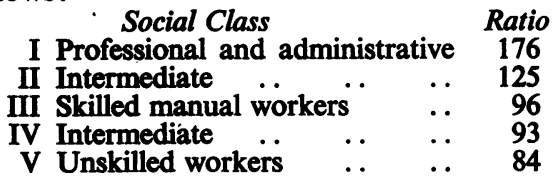

Grouping together Social Classes "I and II" and "IV and V" gives the following ratios:

\begin{tabular}{|c|c|c|}
\hline Age & I and II & IV and $V$ \\
\hline $\begin{array}{l}16-34 \ldots \\
35-64 \ldots \\
65 \text { and } \text { over }\end{array}$ & $\begin{array}{l}1.52 \\
1.41 \\
2.05\end{array}$ & $\begin{array}{l}1 \\
1 \\
1\end{array}$ \\
\hline
\end{tabular}

The social gradient for married women was as great as that for men.

Occupation.- None of the individual occupations distinguished in the Registrar-General's analysis had a significant excess of death from "leukaemia,

\footnotetext{
- The ratios published by the Registrar-General are for the restricted age group 16-64.
}

etc.", but employers and managers as a whole (all in Social Class II) had a mortality ratio as high as that of Social Class I. It is not easy to believe that an occupational factor could explain the high rate among employers and managers; this and the general social gradient are more likely to have resulted from some factor common to all well-paid persons at that time (1930-32). An abbreviated analysis of mortality in the different economic strata of England and Wales has been prepared (RegistrarGeneral, 1954) from the deaths registered during 1950 together with the ONE per cent. sample of the 1951 census records. This agrees with the previous analysis in indicating a social distribution of leukaemia which is:

(i) unfavourabe to the higher income groups,

(ii) more uneven at ages over 65 than during working life.

An economic gradient in leukaemia has been reported from the U.S.A. by Sacks and Seeman (1947), where the excess again occurs at the upper end of the economic scale. In the United States also an occupational risk has been established by March (1950), who estimates that radiologists have a death rate from leukaemia nine times as high as that for other physicians. This implies a very high risk indeed, as the control group used-physicians other than radiologists-are thought by Peller and Pick (1952) to have a death rate from leukaemia about three times as high as that for the general white population.

\section{Trend and Possible Short-Term Changes in LeUKaEMIa MortaltTy}

As measured by the Comparative Mortality Index (which allows for changes in the agecomposition of the population) leukaemia mortality in England and Wales was more than $2 \frac{1}{2}$ times as heavy in 1953 as it had been in 1931. In each sex the course of this Index has been close to an exponential curve, correlation coefficients between the logarithm of the index and time being +0.99 and $+\mathbf{0 . 9 8}$ for males and females respectively. The rates of increase over this period, estimated from fitted curves, were $4 \cdot 3$ per cent. per annum for males, and 4.0 per cent. per annum for females.

Despite the close fit of the annual points to the logarithmic trend, there were significant differences between the actual and "expected" numbers of deaths.* The outstanding years were 1941 and 1948 , in each of which about 10 per cent. of the "expected" deaths failed to occur. In 1941 the

* For the whole period, sexes combined, $\chi^{2}$ with 21 degrees of freedom $=39 \cdot 88, P<0 \cdot 01$. 
deviation from trend applied equally to males and females. In 1948 the deficiency was largely in deaths of females, but an equivalent deficiency of male deaths occurred in the two years 1947-48.

A feature of the rise in leukaemia mortality which has been commented on both by the RegistrarGeneral and by American observers is the disproportionately large rise in the age-specific death rates at ages over 65 . There are many possible interpretations of this phenomenon with, as yet, little to choose between them. It does not necessarily imply any disproportionate exposure of elderly persons to leukaemogenic influences, since the latent period for malignant disease may be 20 years or more.

Leukaemia mortality seems to be little affected by the seasons of the year. Over the 6 years 1948-53 (covering 11,000 deaths), after making due allowance for trend and for differences in the length of months, it was found that the months of highest apparent mortality were June and July, and the lowest April and May. But the range of the apparent fluctuation was hot statistically significant. In this lack of seasonal movement leukaemia differs from most diseases, including other malignant neoplasms.

It seems likely, however, that short term fluctuations of a non-seasonal character do occur, at least in the numbers of male deaths. An examination of fluctuations in the numbers of leukaemia deaths during the 21 quarters up to the end of 1953, after adjustment for trend and for differences in the number of days per quarter, ${ }^{*}$ showed that significant deviations had occurred in male deaths, but not in female deaths. $\dagger$ On three occasions in the figures for males a high quarterly mortality was followed immediately by a low mortality.

In view of the hypothesis that an acute infection may influence the development of leukaemia, a search was made for fluctuation in relation to the one major epidemic affecting adults in recent years, namely the influenza outbreak early in 1951 . Unfortunately the hypothesis gives no guidance regarding the time-lag to be expected. It is also possible that a temporary influence shows its effect, if any, after different intervals for men and for women (a point discussed above). Since the heaviest influenza mortality and sickness benefit

\footnotetext{
- As population estimates are not available for each quarter, the trend had to be fitted to the absolute numbers of deaths. Deaths of service-men and women have not always been included in the published tables of deaths in each month. Demobilization might therefore have affected the quarterly figures, and for this reason the analysis was not carried back further than the end of 1948.

$t \chi^{2}$ with 19 degrees of freedom $=40.46, P<.017$ males;
}

claims during this epidemic occurred in the NorthWest Region of England (Massey and Logan, 1951), Table $\mathrm{V}$ is of interest.

TABLE $\mathrm{V}$

LEUKAEMIA DEATHS IN NORTH WEST REGION OF ENGLAND

\begin{tabular}{|c|c|c|c|c|c|}
\hline \multicolumn{4}{|c|}{ Year } & Males & Females \\
\hline $\begin{array}{ll}1950 & \ldots \\
1951 & \ldots \\
1952 & \ldots \\
1953 & \ldots\end{array}$ & $\begin{array}{l}\cdots \\
\cdots \\
\cdots\end{array}$ & $\begin{array}{l}\cdots \\
\cdots \\
\cdots\end{array}$ & $\begin{array}{l}\ddot{ } \\
\ddot{*} \\
\cdots\end{array}$ & $\begin{array}{l}128 \\
120 \\
168 \\
131\end{array}$ & $\begin{array}{l}123 \\
128 \\
118 \\
153\end{array}$ \\
\hline
\end{tabular}

Comparison of the 1952 deaths for males and the 1953 deaths for females with those of the preceding years suggests that leukaemia mortality in this region had been disturbed. A statistical test confirms that there was a significant variation in the sex ratio of leukaemia deaths in this region during the years $1950-53 .^{*}$

\section{Discussion}

It is well known that by intensive inbreeding strains of mice can be produced which differ sharply in their liability to develop leukaemia. The very rapid increase of this disease in man within the last generation cannot, however, be attributed to genetic influences. We are therefore obliged to look for some new factor (or factors) in the environment, which has been operating for 25 years at least, and possibly since the 1860 s. Men and women appear in general to be equally exposed to this influence, so that the overall increase in mortality is unlikely to be related to such variables as occupation, smoking, or cosmetics. A dietary habit, such as the consumption of a preserved, dyed, or synthetic food, would provide a more plausible hypothesis for investigation, particularly as some dyestuffs are known to be capable of causing malignant change in human cells. Sulphonamides and the newer antibiotics, which some doctors have regarded as possible agents, have not been available long enough to be held responsible for the rising mortality, for the trend of leukaemia has shown no important change since 1931 (and possibly earlier). On the other hand the use of $X$ rays goes back to the beginning of the century. $X$ rays are known to act as a leukaemogen or co-leukomogen on laboratory animals, and are thought to be responsible for the one established example of occupational risk of leukaemia. Gamma radiation has also been incriminated as a cause of

- $\chi^{2}$ with three degrees of freedom $=10 \cdot 81, P<\cdot 02$. 
leukaemia in survivors from the atomic explosions in Japan (Folley, Borges, and Yamawaki, 1952).

The influence should also be one to which residents in the south and south-east of England have been more exposed than those in the north and north-west. It must affect the rich more than the poor, but must by now be widely diffused through society, for the mortality contrast between the most widely separated social groups is less than that between the 1931 and 1953 rates for the community as a whole. The geographical variation within England may have a common source with the social variation, since the areas most affected are those in which the standard of living is highest. But variation in living standards cannot explain all the geographical variations in leukaemia. For example, the gross excess of leukaemia in Denmark by comparison with neighbouring Germany must be attributed to something more specific than the general standard of living. It is not impossible that the higher rate in Denmark may have arisen from an exceptionally wide use of radiography and radiotherapy.

\section{SUMMARY}

The incidence of deaths attributed to leukaemia is shown to have varied greatly:

(a) As between years (1953 more than $2 \frac{1}{2}$ times as high as 1931);

(b) As between different countries (U.S.A. and Denmark $>$ England, Wales and Scotland $>$ Western Germany > Ireland);

(c) As between different regions of England (south > north);

(d) As between economic strata (rich > poor);

(e) As between races in the U.S.A. (white $>$ nonwhite).

In all five of these contrasts the sexes have been affected to an approximately equal extent and the oldest age group has been affected more than any other.
Four anomalous findings are the following:

(i) there is an abrupt increase in the risk of death from leukaemia between the ages of one and two;

(ii) the regional variation within England hardly affects the leukaemia mortality of the County Boroughs;

(iii) the otherwise steady rise in the Comparative Mortality Index appears to have been interrupted in 1941 and again in 1947-48;

(iv) the numbers of male deaths from leukaemia per quarter in recent years show non-random fluctuations which do not appear to be either secular or seasonal.

I should like to express my thanks to Dr. J. W. Webb, at whose suggestion this study was made, and to Dr. A. M. Stewart for advice in preparing the paper.

\section{REFERENCES}

Árd-Chláraitheoir (1950). "Report of T- an Ard-Chlaraitheoir for the Stationery Office, Dublin".

Bufkin, J. H., and Davison, W. C. (1953). J. Pediat., 42, 612.

Cooke, J. V. (1942). J. Amer. med. Ass., 119, 547.

Folley, J. H., Borges, W., and Yamawakł, T. (1952). Amer. J. Med., $13,311$.

Hoffman, E. F., and Gilliam, A. G (1954). Publ. Hlth Rep. (Wash.), $69,1033$.

March, H. C. (1950). Amer. J. med. Sci., 220, 282.

Massey, A., and Logan, W. P. D. (1951). Proc. roy. Soc. Med., $44,790,792$.

National Health Service of Denmark (1953-54). "Causes of Death in the Kingdom of Denmark, 1951 and 1952".

Copenhagen. "Medical Reports for the years 1951 and 1952."

National Office of Vital Statistics (1951-54). "Vital Statistics of the United States, 1949, Parts I and II, publ. 1951; 1950, Vol. I, 1954, and vol. III, 1953." U.S. Govt. Printing Office, Washington.

Nordling, C. O. (1953). Brit. J. Cancer, 7, 68.

Peller, S., and Pick, P. (1952). Amer. J. med. Sci., 224, 154.

Peller, S., and Pick, P. (1952). Amer. J. med. Sci., 224, 154.
Registrar-General for England and Wales (1938). "Decennial Supplement for England and Wales, 1931." Part IIa. Occupational Mortality. H.M.S.O., London.

- Statistical Review. Tables, Part I, Medical for 1950 publ. 1952; 1951, publ. 1953; 1952, publ. 1953; 1953, publ. 1954; H.M.S.O., London.

- (1953). "Statistical Review of England and Wales for the two years 1948-1949. Text, Medical." H.M.S.O., London.

Wales 1951" (1954). "Decennial Supplement for England and Wales 1951." Occupational Mortality, Part 1. H.M.S.O., London. for the Years 1950, 1951, 1952." H.M.S.O., Belfast. 1950, publ. 1952; 1951 and 1952 , publ. 1953 .

Registrar-General for Scotland (1953-54). “Annual Reports for the Years 1950, 1951, 1952." H.M.S.O., Edinburgh. 1950 and 1951, publ. $1953 ; 1952$, publ. 1954.

Sacks, M. S., and Seeman, I. (1947). Blood, $2,1$.

World Health Organization (1951). "Epidemiological and Vital Statistics Report", 4, 198-9 and 270. 